\title{
Effect of Ethanol Root Extract of Equisetum arvense (L) on Urinary Bladder Activity in Rats and Analysis of Principal Plant Constituents
}

\author{
Haiying Zhang ${ }^{1}$, Ning $\mathrm{Li}^{1}$, Kun $\mathrm{Li}^{2,3}$ and Peng $\mathrm{Li}^{1 *}$ \\ ${ }_{1}^{1}$ Department of Urology of Yantai Hill Hospital, No. 91 of Jiefang Road, Yantai City, 264001, ${ }^{2}$ Department of Gynecology and \\ Obstetrics of Affiliated Hospital of Shandong Academy of Medical Sciences, No. 38, Wuyingshan Road, Jinan City, 250031, \\ ${ }^{3}$ Shandong Academy of Medical Sciences, No. 89, Jingshi Road, Jinan City, Shandong Province, 250062, China
}

*For correspondence: Email: lipeng186186@gmail.com

\begin{abstract}
Purpose: To investigate the mechanism of action by which ethanol root extract of Equisetum arvense influences urinary bladder activity in rats, and to characterize the major compounds of the extract. Methods: Ethanol (95\%) was used for hot extraction for $3 \mathrm{~h}$ in a Soxhlet extraction apparatus. A total of 36 female rats were divided into Equisetum arvense root extract-treated group (EA) and control group. Rats in EA group were treated with a standard diet containing $0.2 \%$ of the extract, while rats in the control group were fed with the diet only. After 3 weeks, 12 rats underwent cystometry with $0.2 \%$ acetic acid solution and bladder activity was recorded. In another 12 rats, blood pressure, body weight and adenosine triphosphate were measured. In the remaining 12 rats, $0.2 \%$ acetic acid solution was infused into the bladder and urinary adenosine triphosphate determined before and after the stimulation.

Results: The results showed that during cystometry with acetic acid, the time interval between urinary bladder contractions was shorter and maximum bladder contraction pressure was much greater in rats in the control group, but in the Equisetum arvense group, the changes were much lower. Also in the Equisetum arvense group, plasma adrenaline and noradrenaline levels were lower than for the control group. Furthermore, increase in the levels of urinary adenosine triphosphate was smaller in Equisetum arvense group than in control group.

Conclusion: This study suggests that Equisetum arvense ethanol root extract influences urinary bladder activity by decreasing adenosine triphosphate release, and is therefore a potential therapeutic agent against bladder disorder. However, there is need for further investigation of its exact mechanism of action.
\end{abstract}

Keywords: Equisetum arvense, Bladder activity, Cystometry, Adenosine triphosphate release, adenosine triphosphate, Liquid chromatography-tandem mass spectrometry

Tropical Journal of Pharmaceutical Research is indexed by Science Citation Index (SciSearch), Scopus, International Pharmaceutical Abstract, Chemical Abstracts, Embase, Index Copernicus, EBSCO, African Index Medicus, JournalSeek, Journal Citation Reports/Science Edition, Directory of Open Access Journals (DOAJ), African Journal Online, Bioline International, Open-J-Gate and Pharmacy Abstracts

\section{INTRODUCTION}

In recent years, interest in problems related to urinary bladder control such as overactive bladder and urinary leakage is on a rapid rise. This increased interest may be linked to the increased awareness of the deleterious effect of lower urinary tract symptoms (LUTS) on quality of life as well as the World Health Organization (WHO) sponsored activities related to such issues [1]. Overactive bladder which now is thought to be a chronic condition is defined urodynamically as detrusor overactivity, and characterized by involuntary bladder contractions 
during the filling phase of the micturition cycle [2]. Further, bladder overactivity is also reported in benign prostatic hyperplasia (BPH), which is a common condition in old men characterized by enlargement of the prostate gland and is frequently accompanied by lower urinary tract symptoms (LUTS) and urinary tract obstruction [3]. An increase in sympathetic tone and high blood pressure are reported to complicate LUTS. Further, many published studies suggest that ATP secreted by epithelial cells of the bladder also affects bladder activity.

There are several reports on the efficacy and safety of phytotherapeutic compounds for $\mathrm{BPH}$ and LUTS. Saw Palmetto extract from Serenoa repens is one of the frequently studied and used herbal agents [4]. Further, herbal medicinal agents and their metabolites such as $\beta$-sitosterol, Pygeum (extract from Prunus africana), and Urtica dioica root extract. Gosha-jinki-gan, which is a Chinese herbal medicine has been used for BPH and LUTS. In animal studies using continuous cystometry, Gosha-jinki-gan was reported to increase the interval between bladder contractions and increase bladder capacity [5-8]. However, only a limited number of therapies are available for these urological disorders coupled with the drawbacks of some current therapeutic agents and there is a need for such therapeutic targets which will be effective with less toxicity. Therefore, the objective of this study was to evaluate the effect and possible mechanistic mechanism of action of the ethanol extract of Equisetum arvense on urinary bladder activity in rats and to determine bioactive compounds in the extract.

\section{EXPERIMENTAL}

\section{Materials}

A total of 36 female Sprague-Dawley rats (Dashuo experiment animal center, Chengdu) weighing $150-210 \mathrm{~g}$ were used in this study. The rats were divided into two groups, with a control group of 18 rats and an Equisetum arvense (EA) group of 18 rats. Rats in the control group were fed a standard diet, while animals in the EA group were fed with the same standard diet along with $0.2 \%$ Equiseteum arvense ethanol extract powder. The rats were fed the respective diets for 3 weeks and tap water was freely accessible to them during this period. The animals were maintained in accordance with the U.S. National Institutes of Health Guide for the Care and Use of Laboratory Animals $(\mathrm{NIH}$ Publication 80-23, revised 1996) and all procedures were approved by the Ethical Committee of the General Hospital of Chengdu Military Region (approval ref no. IECA/GHC/2013/097).

\section{Plant material and preparation of the extract}

The roots of $E$. arvense were collected during May - June 2013 from Jiuzhaigou, Chengdu, China. The plant material was identified by Prof Long Qing-De of the Guiyang Medical University Department of Medicine, and a voucher specimen (no. GMU-0077654) was deposited at the herbarium of Guiyang Medical University, Guiyang, China. The roots were thoroughly washed with tap water, shade dried and then chopped into small pieces. Ethanol (95\%) was used for hot extraction carried out for $3 \mathrm{~h}$ using a Soxhlet extractor. The extract was then concentrated under reduced pressure in a rotary evaporator at $40{ }^{\circ} \mathrm{C}$ and was then kept in a refrigerator at $4{ }^{\circ} \mathrm{C}$ prior to use.

\section{Body weight measurement and continuous cystometry}

After 3 weeks of feeding, 12 rats, 6 in the control group and 6 in the EA group, were anesthetized with urethane $(0.5 \mathrm{gm} / \mathrm{kg}$ and $0.3 \mathrm{gm} / \mathrm{kg}$ subcutaneously and intraperitoneally respectively) and the body weight was measured. To perform continuous cystometry, a PE-50 polyethylene catheter was injected into the bladder through the urethra. Physiological saline was infused through the catheter and bladder activity was measured through the urethral catheter, which was connected to a pressure transducer and a saline infusion pump via a 3-way stop cock. Cystometry was continued for at least $50 \mathrm{~min}$ and the interval between bladder contractions, maximum bladder contraction pressure, intravesical baseline pressure and bladder contraction time were monitored and measured during the final 30 minutes. These rats were also subjected to continuous cystometry with $0.2 \%$ acetic acid solution after continuous cystometry with physiological saline was complete. Here again, continuous cystometry with $0.2 \%$ acetic acid solution was continued for $50 \mathrm{~min}$ and similar measurements were performed.

\section{Evaluation of biochemical profile and blood pressure}

In the other 12 rats including 6 each from the control and EA groups, blood pressure measurement and biochemical tests were carried 
out. Blood pressure was measured in conscious and restrained rats by the tail cuff method using a BP-98A sphygmomanometer. The blood pressure was measured as the mean of 3 recordings obtained at 1 -min time periods.

After this, each rat was anesthetized with $1.5 \%$ halothane and blood was withdrawn. The blood sample was centrifuged followed by measurement of the noradrenaline, adrenaline, dopamine and serotonin levels in blood plasma using high performance liquid chromatography (HPLC) in combination with tandem mass spectrometry.

\section{Adenosine triphosphate (ATP) measurement}

From the remaining 12 rats, including 6 rats each from control group and 6 rats from EA group, urine samples were collected. After this, the rats were anesthetized with $1.5 \%$ halothane while 2 $\mathrm{ml}$ of $0.2 \%$ acetic acid solution was infused into the bladder through a catheter for $15 \mathrm{~min}$ to provide stimulation. To prevent any urinary tract infection, the rats were injected subcutaneously with $100 \mathrm{mg}$ cefazolin sodium hydrate. Spontaneously voided urine was also collected at 3-6 h (day 0) after recovery from halothane anesthesia as well as on days 2, 4 and 6 after the bladder stimulation. Urinary ATP was measured using an ATP Hygiene kit $\mathrm{HS}$ and Gene Light 55.

\section{Liquid chromatography-tandem mass spectrometry (LC-ESI-MSMS)/HPLC analysis}

LC-MS equipment (LC-MS QqQ-6410B Agilent Technologies) consisted of a chromatographic system (1260 Infinity Agilent Technologies) coupled with an Agilent Triple Quad mass spectrometer fitted with an ESI source. MS conditions were the following: MS range 1001200 Da, MSn spectra were obtained using both positive and negative modes, nebulizer gas 45 Psi, gas temperature $325^{\circ} \mathrm{C}$, capillary voltage $4000 \mathrm{~V}$

HPLC analysis was carried out by an Agilent 1260 infinity series. A Chromolith RP-18e column (4.6 mm ID, $50 \mathrm{~mm}$ length) (Merck) was used. Mobile phase consisted of $(A)$ aqueous formic acid $(0.1 \%)$ and (B) methanol. Gradient condition was; 0-8 min, linear gradient from 12 to $25 \%$ of $\mathrm{B} ; 8-12 \mathrm{~min}$, isocratic conditions at 25 $\%$ of $B ; 12-16 \mathrm{~min}$, linear gradient from 25 to 40 $\%$ of B; $16-40 \mathrm{~min}$, linear gradient from 40 to 50 $\%$ of $\mathrm{B}, 40-50 \mathrm{~min}$, linear gradient from 50 to $100 \%$ of $\mathrm{B}$. Flow rate was $1 \mathrm{ml} / \mathrm{min}$.

\section{Statistical analysis}

The results are reported as mean \pm standard deviation (SD). Slide write Plus version 7.01 was used for analysis of the data while Student's unpaired t-test was applied for statistical analysis with $p<0.05$ considered to be statistically significant.

\section{RESULTS}

\section{Effect of EA on the body weight of rats}

There was no remarkable difference between the body weights of the control and EA group of rats before the experiment was initiated. However, after 3 weeks of feeding on EA diet, body weight of the rats in the EA group was remarkably increased in comparison to the control diet group rats (Table 1$)(10 \%$ increase, $p=0.015)$

\section{Continuous cystometry}

There was no considerable difference in the time interval between bladder contractions, intravesical baseline pressure, bladder contraction time and residual urine volume between the EA group and control group rats during continuous cystometry with physiological saline. However, it is important to mention that maximum bladder contraction pressure was considerably lower by $21.7 \%$ in the control group as compared to the EA group ( $p=0.01$, Table 1$)$. However, during the continuous cystometry with $0.2 \%$ acetic acid solution, it was observed that the time interval between urinary bladder contractions became considerably shorter by $18.5 \%(p=0.02)$ and maximum bladder contraction pressure was significantly higher by $7.4 \%(p=0.01)$ in the control group as compared to the EA group (Fig 1).

\section{Biochemical profile and blood pressure}

It was also observed that there were no considerable differences in the bladder weight and systolic, mean and diastolic blood pressure between the two groups (control group and EA group). The biochemical tests revealed that there were small differences in the plasma dopamine, ATP and serotonin between the two groups. But it was revealed that plasma adrenaline and noradrenaline concentrations were significantly higher by 38.7 and $41.2 \%$ in the control group as compared to the EA group $(p<0.01$ and $p<$ 0.05 , respectively, Table 2 ). 

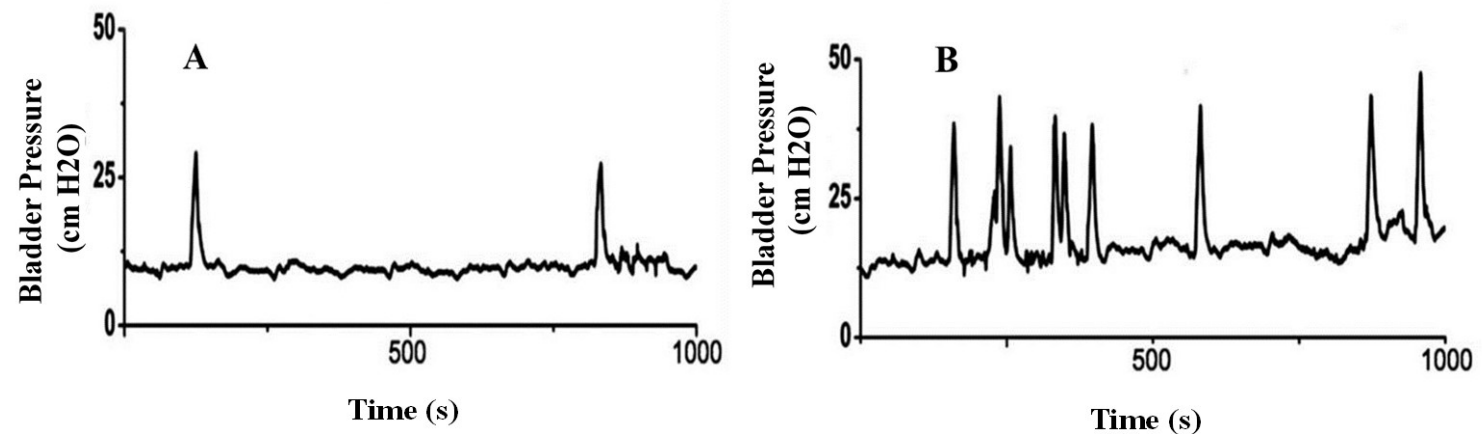

Time (s)
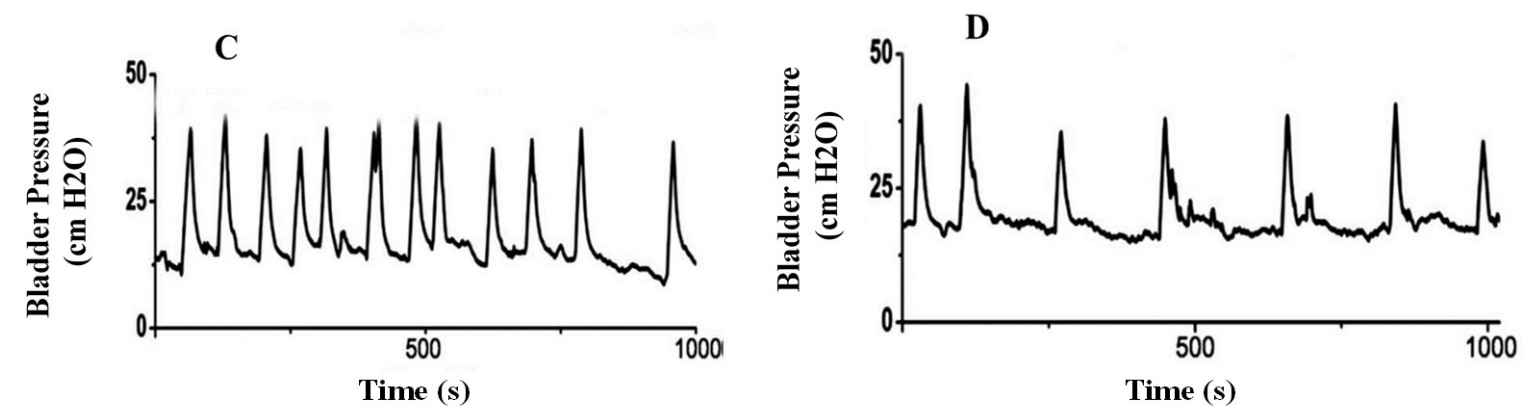

Figure 1: Intravesical infusion of $E$. arvense extract resulted in increased voiding frequency (decreased intercontraction interval). Representative continuous cystometrogram recordings in rats treated with intravesical protamine sulfate in control rats $(A)$ and different concentrations of the extract (B-D).

Table-1: Impact of Equisetum arvense ethanol extract on continuous cystometry with physiological saline or 0.2 $\%$ acetic acid

\begin{tabular}{|c|c|c|c|c|}
\hline Group & $\begin{array}{l}\text { Interval (min) } \\
(\text { mean } \pm \text { SD) }\end{array}$ & $\begin{array}{c}\text { Maximum } \\
\text { Bladder } \\
\text { Contraction } \\
\text { Pressure }(\mathrm{cm} \\
\left.\mathrm{H}_{2} \mathrm{O}\right) \\
{\text { (mean } \pm \mathrm{SD})^{\mathrm{b}}}\end{array}$ & $\begin{array}{l}\text { Baseline intravesical } \\
\text { pressure }\left(\mathrm{cm} \mathrm{H}_{2} \mathrm{O}\right) \\
(\text { Mean } \pm \mathrm{SD}){ }^{\mathrm{c}}\end{array}$ & $\begin{array}{c}\text { Duration (min) } \\
\text { (mean } \pm \text { SD) }\end{array}$ \\
\hline \multicolumn{5}{|l|}{ Physiological saline } \\
\hline Control & $6.2 \pm 0.9$ & $44.2 \pm 5.4$ & $6.4 \pm 1.3$ & $0.9 \pm 0.3$ \\
\hline $\begin{array}{l}\text { Equisetum arvense (EA) } \\
\text { Acetic acid solution (0.2\%) }\end{array}$ & $8.1 \pm 1.2$ & $51.3 \pm 8.8$ & $7.9 \pm 1.6$ & $0.9 \pm 0.3$ \\
\hline Control & $3.9 \pm 1.2$ & $48.6 \pm 1.7$ & $5.9 \pm 1.6$ & $0.9 \pm 0.4$ \\
\hline Equisetum arvense (EA) & $7.3 \pm 1.7$ & $49.3 \pm 2.1$ & $8.1 \pm 2.1$ & $1.3 \pm 0.3$ \\
\hline
\end{tabular}

${ }^{\mathrm{a}} p<0.01 ;{ }^{\mathrm{b}} p<0.01 ;{ }^{\mathrm{c}} p<0.05$

Table-2: Effect of Equisetum arvense ethanol root extract on blood pressure and bladder weight

\begin{tabular}{llcc}
\hline Parameter & $\begin{array}{c}\text { Control } \\
\text { (mean } \pm \text { SD) }\end{array}$ & $\begin{array}{c}\text { Equisetum arvense } \\
\text { (mean } \pm \text { SD) }\end{array}$ \\
\hline Blood pressure & Systolic & $101 \pm 4$ & $109 \pm 5$ \\
(mm Hg) & Mean & $94 \pm 4$ & $97 \pm 3$ \\
& Diastolic & $81 \pm 3$ & $86 \pm 3$ \\
Bladder weight $(\mathrm{g})$ & & $0.16 \pm 0.03$ & $0.15 \pm 0.01$ \\
\hline
\end{tabular}

\section{Urinary ATP measurement}

Before acetic acid solution infusion into the bladder, the measured urinary ATP revealed no differences between the control group and EA group. However, after the $0.2 \%$ acetic acid solution infusion into the bladder, the urinary ATP-to-CRE (CRE = creatinine) ratio was considerably higher on days 0 to 3 with a 5,556
$\%, 429 \%$ and $150 \%$ increase in the control group as compared with the level before acetic acid infusion $(p=0.01, p<0.001$ and $p<0.05$ respectively, Fig 1 and Table 3). In the EA group, the urinary ATP-to-CRE ratio was also considerably higher on days 0 and 1 with a 3,432 $\%$ and $150 \%$ increase compared with that before acetic acid solution infusion $(p<0.01$ and $p<$ 0.012 respectively, Fig. 1 and Table 3 ). However, 
on comparing the control group with the EA group after acetic acid infusion, it appeared that the urinary ATP-to-CRE ratio was significantly higher on days $0-3$ in the control group as compared to the EA group. However, after 6 days the urinary ATP-to-CRE ratio shifted to baseline and no difference was observed between the two groups (control and EA group).

\section{Major compounds of extract}

The phytochemical analysis of the $E$. arvense root ethanol extract was carried out by LC-ESIMS as well as HPLC-DAD techniques. The extract was run under both positive and negative ESI-MS conditions and it showed several major and minor ionic species. The seven chemical constituents identified were apigenin (1), luteolin
(2), luteolin-5-O- $\beta$-D-glucopyranoside (3), isoquercetin (4), apigenin-5-O-glucoside (5), ursolic acid (6), and oleanolic acid (7) (Fig 2).

These phytochemicals have already been reported previously in this medicinal plant [9-12]. The total ion MS chromatogram (TIC) and HPLC 3-D plot are shown in Figs 3 and 4, respectively. The minor peaks in the chromatogram corresponded to some impurity with unusual mass fragmentation pattern, hence were not identified. Fragmentation of the major peaks was used for the identification of compounds. The identification of the chemical compounds was also carried out by comparing the molecular ion peaks along with the MS fragmentation pattern with those of the literature.<smiles>O=c1cc(-c2ccc(O)cc2)oc2cc(O)cc(O)c12</smiles>

Apigenin (1)<smiles>O=c1cc(-c2ccc(O)c(O)c2)oc2cc(O)cc(O)c12</smiles><smiles>O=c1cc(-c2ccc(O)c(O)c2)oc2cc(O)cc(O[C@@H]3O[C@H](CO)[C@@H](O)[C@H](O)[C@H]3O)c12</smiles><smiles>O=c1c(OC2OC(CO)C(O)C(O)C(O)C2O)c(-c2ccc(O)c(O)c2)oc2cc(O)cc(O)c12</smiles>
Isoquercetin (4)

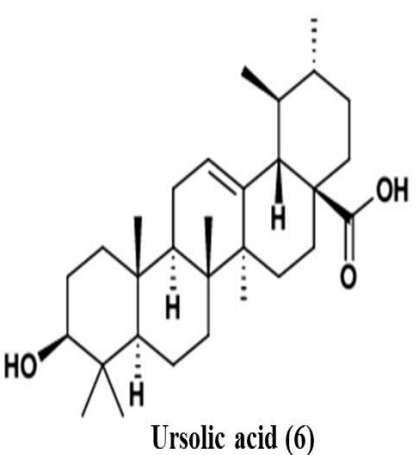

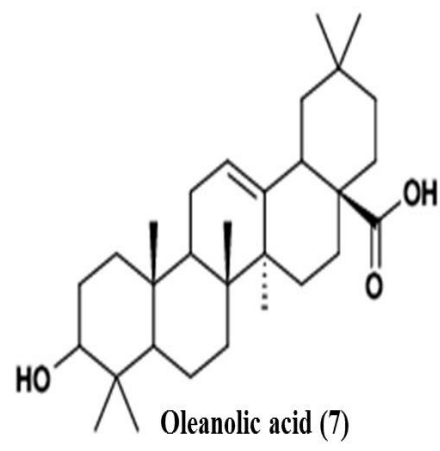

Fig 2: Phytochemical constituents identified in the ethanol root extract of Equisetum arvense

Table 3: Effect of Equisetum arvense ethanol root extract on the biochemical profile of rat

\begin{tabular}{lll}
\hline Parameter & $\begin{array}{l}\text { Control } \\
\text { (mean } \pm \text { SD) }\end{array}$ & $\begin{array}{l}\text { Equisetum extract } \\
\text { (mean } \pm \text { SD) }\end{array}$ \\
\hline Serotonin $(\mathrm{pg} / \mathrm{ml})$ & $2,186 \pm 350$ & $1,877 \pm 544$ \\
Dopamine $(\mathrm{pg} / \mathrm{ml})$ & $297 \pm 46$ & $221 \pm 54$ \\
Adrenaline $(\mathrm{pg} / \mathrm{ml})$ & $19,006 \pm 5500$ & $12,051 \pm 3561^{\mathrm{a}}$ \\
Noradrenaline $(\mathrm{pg} / \mathrm{ml})$ & $2,305 \pm 643$ & $1,231 \pm 321^{\mathbf{D}}$ \\
\hline
\end{tabular}


Table 4: Effect of ethanol extract of Equisetum arvense extract on urinary ATP level after $0.2 \%$ acetic acid stimulation

\begin{tabular}{llll}
\hline Variable & $\begin{array}{l}\text { Mean } \mathbf{l} \text { SD ATP } \\
\text { (mol/mg CRE x E-10) }\end{array}$ & \\
\cline { 2 - 4 } & Control & Equisetum extract & P value \\
\hline $\begin{array}{l}\text { Before 0.2\% acetic acid } \\
\text { stimulation }\end{array}$ & $12.2 \pm 7.6$ & $6.7 \pm 5.4$ & \\
After 0.2\% acetic acid & & & \\
stimulation & & $321.6 \pm 211.2$ & $<0.05$ \\
Day 0 & $726.9 \pm 432.12$ & $44.5 \pm 21.4$ & $>0.01$ \\
Day 1 & $87.1 \pm 32.5$ & $14.31 \pm 4.6$ & $>0.01$ \\
Day 2 & $35.28 \pm 11.6$ & $7.5 \pm 2.7$ & $>0.05$ \\
Day 3 & $32.1 \pm 11.7$ & $2.1 \pm 1.3$ & $>0.05$ \\
Day 7 & $6.5 \pm 3.2$ & & \\
\hline
\end{tabular}

$A T P=$ Adenosine triphosphate, $C R E=$ Creatinine, $A T P$-to-CRE $(C R E=$ creatinine $)$

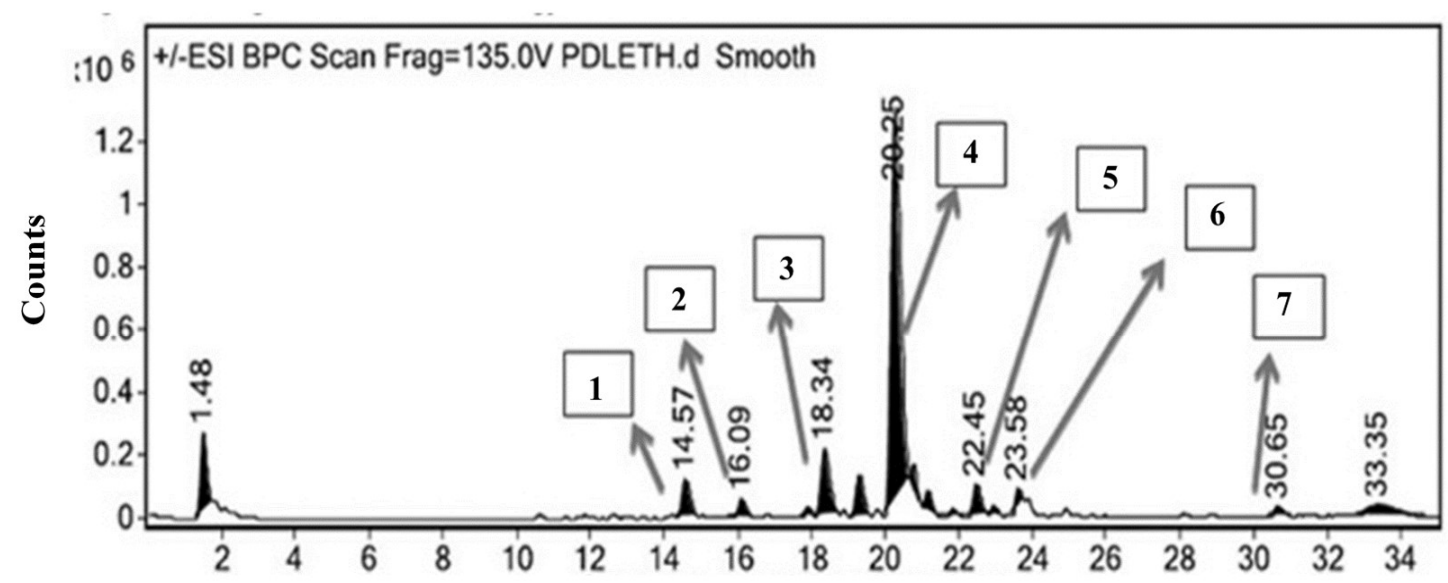

Acquisition Time (min)

Fig 3: LC-MS chromatogram of the ethanol extract of Equisetum arvense indicating the different peaks for the pytochemical constituents

\section{D-Plot}

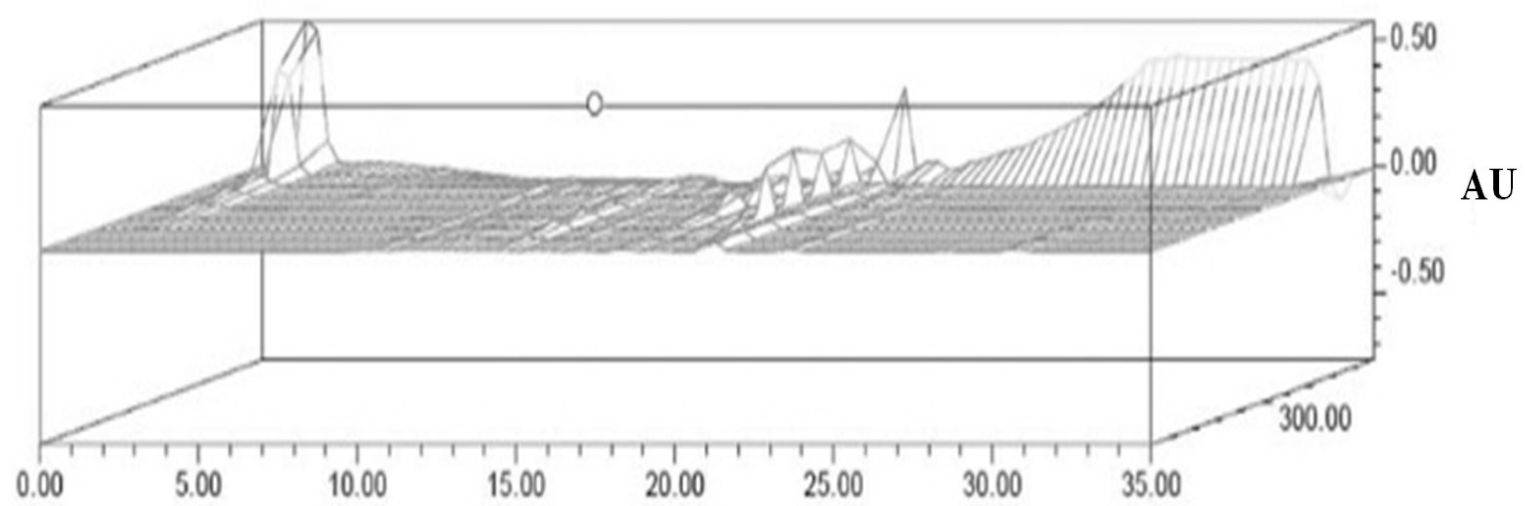

Time (minutes)

Fig 4: HPLC 3-D plot of the bioactive extract of Equisetum arvense 


\section{DISCUSSION}

Many disorders today are being treated using complementary and alternative medicine, and consumption of herbal ingredients is on a rise globally, mainly due to the viewpoint that herbal medicines have less side-effects compared to orthodox medicines. Serenoa repens is one such herbal medicinal agent used against various urological disorders. Published literature reveals that men with $\mathrm{BPH}$ exhibited a significant improvement in the urinary peak flow rate and decreased nocturia after the administration of Serenoa repens, which is a lipid sterol extract from dwarf palms [13].

In a one-year international study, comparing Serenoa repens with an $\alpha$-1-adrenergic receptor antagonist for $\mathrm{BPH}$, it was observed that both have an equivalent effect in men with $\mathrm{BPH}$ and LUTS for one year [14]. Another traditional Kampo drug called Gosha-jinki-gan, which comprises of 10 medicinal herbs, is also considered very effective for various urological disorders like LUTS $[15,16]$.

In one study, Gosha-jinki-gan was reported to increase the interval between bladder contractions and enhance capacity of the bladder. This drug is thought to have anticholinergic activity, which is capable of blocking bladder contraction induced by cholinergic nerve stimulation. Eviprostat, another herbal drug which is a cocktail of many medicinal plant extracts, has the effect of decreasing urethral pressure and increasing voided volume. This cocktail has also been reported to inhibit edema in the prostate gland and inflammation of the bladder mucosa in BPH patients [17]. The medicinal plants comprising eviprostat were initially used as folk medicine for many urological symptoms like $\mathrm{BPH}$, cystitis, epididymitis, prostatitis etc.

In this study, we have tried to delineate the effects of $E$. arvense and its influence rat bladder activity by carrying out a set of examinations, comprising of continuous cystometry, biochemical tests, urinary ATP and blood pressure measurement. No such previous reports are documented in the literature on this medicinal plant. We evaluated the changes in the body weight caused by the administration of EA diet. It was observed that on EA administration, plasma catecholamine concentration was lowered. Furthermore, plasma adrenaline and noradrenaline concentrations were considerably lower in the EA group as compared to the control group. During continuous cystometry with physiological saline, maximum bladder contraction pressure was significantly lower in the control group as compared to EA group. This may be due to the effect of Equisetum arvense on the bladder, bladder neck and urethra. The effect of the decrease in adrenaline, noradrenaline and urinary ATP levels is reflected in the difference between maximum bladder contraction pressure of control (44.2) and EA group (51.3).

Further, in order to create a bladder inflammation model, $0.2 \%$ acetic acid solution was infused into the bladder. With acetic acid solution continuous cystometry, the time interval between bladder contractions became significantly shorter and maximum bladder contraction pressure was much higher in the control group in comparison to physiological saline group. However, no considerable differences in the cystometric parameters between the infusion of physiological saline and $0.2 \%$ acetic acid were observed in EA group. In this study, we also observed that EA treatment inhibits an increase in the urinary ATP-to-CRE ratio after bladder stimulation. It is also well known that acetylcholine and ATP are produced by bladder epithelial cells (17). It has also been reported recently that ATP secreted by bladder epithelial cells might influence bladder activity. Therefore, the inhibitory effect of EA on bladder activity may be linked to blocking ATP release from the bladder epithelial cells. Furthermore, the level of bladder activation may be recognized by using increased urinary ATP release as a marker. Equisetum arvense has been reported to act as a potent radical scavenger and these radical scavenging capabilities may contribute to their antiinflammatory action and blocking of ATP release. Apart from the effects of EA on bladder activity, photochemical analysis of EA by ESI-MS showed several major and minor ionic species. The seven chemical constituents identified were apigenin (1), luteolin (2), luteolin-5-O- $\beta$-Dglucopyranoside (3), isoquercetin (4), apigenin-5O-glucoside (5), ursolic acid (6), and oleanolic acid. These will need to be evaluated for their biological effects in future studies.

\section{CONCLUSION}

The findings of this study suggest that Equisetum arvense ethanol root extract influences the urinary bladder activity by decreasing adenosine triphosphate release and thus can potentially be used as a therapeutic agent against bladder disorder. It may find application in the therapeutic efforts to reduce overactivty of urinary bladder which has only a limited number of therapies available at present. 


\section{ACKNOWLEDGEMENT}

The authors would like to thank Shandong Province Natural Science Foundation of China (project no. ZR2009CL027), Science and Technology Star Plans Foundation of Jinan Technology Bureau of China (project no. 20100118) as well as Medical Foundation of Shandong Academy of Medical Science (project no. 201023) for providing financial support for this research work.

\section{REFERENCES}

1. Gurocak S, Kupeli B. Consumption of historical and current phytotherapeutic agents for urolithiasis: $A$ critical review. J Urol 2006; 176(2): 450-455.

2. Gillespie Jl. Noradrenaline inhibits autonomous activity in the isolated guinea pig bladder. BJU Int 2004; 93(3): 401-409.

3. Garraway WM, Collins GN, Lee RJ. High prevalence of benign prostatic hypertrophy in the community. Lancet 1991; 338(8765): 469-71.

4. Bent $S$, Kane $C$, Shinohara $K$, Neuhaus J, Hudes ES, Goldberg H, Avinis AL. Saw Palmetto for Benign Prostatic Hyperplasia. N Engl J Med 2006; 354(6): 557-66.

5. Wilt T, Ishani A, MacDonald R, Stark G, Mulrow C, Lau J. Beta-sitosterols for benign prostatic hyperplasia. Cochrane Database Syst Rev 2000; (2): CD001043.

6. Wilt T1, Ishani A, Mac Donald R, Rutks I, Stark G. Pygeum africanum for benign prostatic hyperplasia. Cochrane Database Syst Rev 2002; (1): CD001044.

7. Nishijima S, Sugaya K, Miyazato M, Ogawa Y. Effect of Gosha-Jinki-Gan, a Blended Herbal Medicine, on Bladder Activity in Rats. J Urol 2007; 177(2): 762765.

8. Do Monte FH, dos Santos JG Jr, Russi M, Lanziotti VM, Leal LK, Cunha GM. Antinociceptive and antiinflammatory properties of the hydroalcoholic extract of stems from Equisetum arvense $L$. in mice. Pharmacol Res 2004; 49(3): 239-243.

9. Suzuki K, Homma T. Isolation and chemical structure of flavonoids from horsetail (Equisetum arvense L). J Adv Sci 1997; 9: 104-105.

10. Pietta P, Mauri P, Bruno A, Rava A, et al. Identification of flavonoids from Ginkgo biloba $L$., Anthemisnobilis $L$. and Equisetum arvense L. by high-performance liquid chromatography with diode-array UV detection. J Chromatogr 1991; 553: 223-31.

11. Ganeva Y, Chanev C, Dentchev T. Triterpenoids and sterols from Equisetum arvense. Dokladina Bulgarskata Akademiya na Naukite 2001; 54(2): 5356.

12. Boyle P, Robertson C, Lowe F, Roehrborn C. Updated meta-analysis of clinical trials of Serenoarepens extract in the treatment of symptomatic benign prostatic hyperplasia. BJU Int 2004; 93(6): 751-6.

13. Debruyne F, Koch G, Boyle P, Da Silva FC, Gillenwater JG, Hamdy FC, Perrin P, Teillac P, Vela-Navarrete R, Raynaud JP. Comparison of a phytotherapeutic agent (Permixon) with an alpha-blocker (Tamsulosin) in the treatment of benign prostatic hyperplasia: a 1-year randomized international study. Eur Urol 2002; 41(5): 497-506.

14. Fuse $H$, Akashi $T$. Chinese medicine for treatment of patients with prostatic hyperplasia. Nihon Rinsho 2002; 60(Supp/ 11): 362-6.

15. Tokunaga S, Nakashima T, Yamaguchi K, Nishikawa $T$, Lee S-W, Morishita H, Uchibayashi T, Ohkawa M, Hisazumi $H$. Clinical evaluation of Gosha-jinki-gan in patients with urinary disturbance. Nishinihon $\mathrm{J}$ Urol 1992; 54: 1067.

16. Yoshida $M$, Murakami S, Inadome A, Masunaga $K$, Miyamae K, Otani M, Iwashita $H$, Ueda S. Effects of age and muscle stretching on acetylcholine release in isolated human bladder smooth muscles. J Urol 2002; 167: 40.

17. Andersson KE, Yoshida M. Antimuscarinics and the overactive detrusor: which is the main mechanism of action? Eur Urol 2006; 43(1): 1. 